\title{
Fractal behavior in continental crustal heat production
}

\author{
N. Vedanti, R. P. Srivastava, O. P. Pandey, and V. P. Dimri \\ National Geophysical Research Institute, Council of Scientific and Industrial Research, Uppal Road, \\ Hyderabad 500 007, India \\ Received: 21 July 2010 - Revised: 18 December 2010 - Accepted: 15 January 2011 - Published: 17 February 2011
}

\begin{abstract}
The distribution of crustal heat production, which is the most important component in the elucidation of continental thermal structure, still remains a theoretical assumption. In general the heat production values must decrease with depth, but the form of decrease of heat production in the crust is not well understood. The commonly used heat production models are: "block model", in which heat production is constant from the surface to a given depth and the "exponential model", in which heat production diminishes as an exponential function of depth. The exponential model is more widely used wherein sources of the errors are heterogeneity of rock and long wavelength changes due to changes in lithology and tectonic elements, and as such exponential distribution does not work satisfactorily for the entire crust. In the present study, we analyze for the first time, deep crustal heat production data of six global areas namely Dharwar craton (India), Kaapvaal craton (South Africa), Baltic shield (Kola, Russia), Hidaka metamorphic belt (Japan), Nissho pluton (Japan) and Continental Deep Drilling site (KTB, Germany). The power spectrum of all the studied data sets exhibits power law behaviour. This would mean slower decay of heat production with depth, which conforms to the known geologic composition of the crust. Minimum value of the scaling exponent has been found for the KTB borehole, which is apparently related to higher heat production of gneisses, however for other study areas, scaling exponent is almost similar. We also found that the lower values of scaling exponents are related to higher heat production in the crust as is the case in KTB. Present finding has a direct relevance in computation of temperature-depth profiles in continental regions.
\end{abstract}

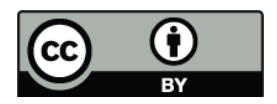

Correspondence to: $\mathrm{N}$. Vedanti (nimisha@ngri.res.in)

\section{Introduction}

Of the parameters to which heat flow is related, radioactive heat production of the crustal rocks is one of the most important. It is main source of the terrestrial heat flow and any anomaly within the heat flow province is largely attributed to the differences in heat producing elements of the crustal rocks. It contributes to about $50 \%$ of the observed heat flow at the surface and is considered a critical parameter in elucidation of deeper temperature regime.

Radioactive heat production $(A)$ depends upon the amount of Uranium "U", Thorium "Th", and Potassium "K" present in the rock. $\mathrm{U}$ and $\mathrm{Th}$ are normally present as trace elements and their concentration does not exceed a few tens of parts per million (ppm), while $\mathrm{K}$ is present as a major oxide. Heat production is known to be highest in acid rocks and lowest in ultrabasics. Consequently, the upper parts of the crust have higher heat production compared to extremely low values in the underlying lower crust and upper mantle.

In the absence of direct sub-surface measurements, various radioactive heat production models have been proposed in the literature for the distribution of radioactive heat sources with depth. This includes the exponential model which has been very widely used. In this model, the heat production $(A)$ and depth $(z)$ are related as

$A(z)=A_{0} \exp (-z / D)$

where $D$ is the logarithmic decrement for an exponentially decreasing radioactive concentration (Lachenbruch, 1968, 1970). However, our study based on six deep continental crustal sections round the globe, does not support exponential decay at mid crustal depths characterized by intermediate composition. For example, Vredefort granitic basement (Kaapvaal craton, South Africa) (Table 1), as discussed later.

Published by Copernicus Publications on behalf of the European Geosciences Union and the American Geophysical Union. 
Table 1. Variation of heat production $\left[A(z), \mu \mathrm{W} \mathrm{m}{ }^{-3}\right]$ variation with depth $(\mathrm{km})$ in various continental crustal regions.

\begin{tabular}{|c|c|c|c|c|c|c|c|c|c|}
\hline \multicolumn{2}{|c|}{$\begin{array}{l}\text { Dharwar } \\
\text { Craton, (South Indian Shield) }\end{array}$} & \multicolumn{2}{|c|}{$\begin{array}{l}\text { North Eastern } \\
\text { Baltic Shield }\end{array}$} & \multicolumn{2}{|c|}{$\begin{array}{l}\text { Vredefort basement, } \\
\text { (Kaapvaal craton) }\end{array}$} & \multicolumn{2}{|c|}{$\begin{array}{l}\text { Hidaka metamorphic belt } \\
\text { (Japan) }\end{array}$} & \multicolumn{2}{|c|}{$\begin{array}{l}\text { Nissho pluton } \\
\text { (Japan) }\end{array}$} \\
\hline Depth & $A(z)$ & Depth & $A(z)$ & Depth & $A(z)$ & Depth & $A(z)$ & Depth & $A(z)$ \\
\hline 8.0 & 4.8 & $6.84-7.62$ & 1.40 & $6-7$ & 2.153 & $7.54-11.1$ & 0.70 & 1.24 & 2.77 \\
\hline 8.2 & 4.56 & $7.62-9.46$ & 1.13 & $7-8$ & 2.374 & $11.1-17.1$ & 0.91 & 1.69 & 2.18 \\
\hline 8.46 & 4.85 & $9.46-9.57$ & 2.36 & $8-9$ & 2.408 & $17.1-20.9$ & 0.43 & 2.04 & 2.87 \\
\hline 8.73 & 2.38 & $9.57-10.14$ & 1.56 & $9-10$ & 2.123 & $20.9-25.0$ & 0.49 & 2.89 & 2.07 \\
\hline 8.96 & 3.02 & $10.14-10.6$ & 2.23 & $10-11$ & 1.542 & & & 4.11 & 2.05 \\
\hline 9.20 & 3.31 & $10.6-11.4$ & 1.60 & $11-12$ & 1.488 & & & 4.58 & 2.03 \\
\hline 9.45 & 2.71 & $11.4-11.7$ & 2.12 & $12-13$ & 0.865 & & & 4.75 & 2.69 \\
\hline 9.70 & 2.71 & $12.0-20.0$ & 1.10 & $13-14$ & 0.869 & & & 5.09 & 1.29 \\
\hline 9.98 & 2.34 & $20.0-30.0$ & 0.60 & $14-15$ & 1.078 & & & 5.13 & 1.24 \\
\hline 11.72 & 1.83 & $30.0-40.0$ & 0.15 & $15-16$ & 1.095 & & & 5.67 & 1.30 \\
\hline 13.47 & 1.53 & & & $16-17$ & 1.049 & & & 6.44 & 1.16 \\
\hline 15.22 & 1.51 & & & $17-18$ & 0.945 & & & 6.73 & 1.42 \\
\hline 16.99 & 1.34 & & & $18-19$ & 0.823 & & & 6.84 & 1.90 \\
\hline 20.00 & 1.06 & & & $19-20$ & 0.970 & & & 7.01 & 0.93 \\
\hline 21.00 & 0.78 & & & & & & & & \\
\hline 24.00 & 0.50 & & & & & & & & \\
\hline 32.5 & 0.16 & & & & & & & & \\
\hline
\end{tabular}

\section{Crustal heat production profiles}

Except for the KTB borehole, which is well documented in literature, all other heat production data used in the present study are given in Table 1. Salient features of these regions and data sources are given below.

\subsection{Dharwar Craton (Southern India)}

Dharwar craton of the southern Indian shield is considered one of the largest among the Archean cratons of the world. It exposes a tilted $30 \mathrm{~km}$ thick section of deep continental crust representing upper, middle and lower Archean crust. Present day exposed crustal configuration comprises four metamorphic facies layers, green schist, amphibolites, metasomatized granulite and depleted granulites. Heat production vs. depth distribution has been studied in detail for the Closepet granitic batholithic region (Senthil Kumar and Reddy, 2004) situated in the central part of the craton which itself exposes almost $12 \mathrm{~km}$ deep section corresponding to palaeo-depth between 8 and $20 \mathrm{~km}$. To this data, we have added, the recently acquired heat production data pertaining to sub-surface mid-crustal amphibolite-granulite facies rocks from Killari region (Maharashtra, India) belonging to similar terrain, and lower crustal granulitic heat production data from the Southern granulite terrain of south India (Ray et al., 2003).

\subsection{Northeastern Baltic shield (Europe)}

Measured radioactive heat production data is available from the Kola super deep borehole drilled in the northeastern part of the Baltic shield (Kremenetsky et al., 1989) which has been supplemented by a set of data obtained at various erosional levels from other deep boreholes in the region which corresponds to a depth of $25-30 \mathrm{~km}$ and further extrapolated till the Moho. In the present study, we utilize the data corresponding to the stable Archean portion of the crust extending between 6.84 and $40 \mathrm{~km}$ depth (Kremenetsky et al., 1989).

\subsection{Vredefort basement, Kaapvaal craton (South Africa)}

This region is located about $90 \mathrm{~km}$ southwest of Johannesburg. Due to palaeo-geotectonic processes, this region exposes almost $15 \mathrm{~km}$ thick vertical section of the Archean crystalline crust due to overturning of Vredefort granitic basement, thus provided a unique opportunity of measuring deep crustal radioactive heat production. Vertical distribution of the crustal radioactivity for this area has been reported in detail by Nicolaysen et al. (1981). Upper $6 \mathrm{~km}$ of stratified strata (sediments/lavas) which overlies the granitic basement has been excluded from the present study.

\subsection{Hidaka Metamorphic belt (Hokkaido, Japan)}

This zone also exposes a deep continental crustal section as a result of geotectonic movement and erosional processes, 
associated with the collision of the western and eastern Hokkaido blocks. For this region, heat production vs. depth profile is taken from Furukawa and Uyeda (1989). For the present study, the data pertaining to the sediments have been excluded.

\subsection{Nissho Pluton, Hidaka Terrain (Hokkaido, Japan)}

This pluton forms one of the important plutons of this region occupying an area of about $8 \mathrm{~km}$ by $30 \mathrm{~km}$. It is made up of granitic intrusion comprising granite, granodiorite, monzogranite and gneisses. Heat production vs. depth profile for this region is also adopted from Furukawa and Uyeda (1989).

\subsection{KTB borehole (Germany)}

This $9.1 \mathrm{~km}$ deep borehole was drilled through the crystalline rocks at the western margin of the Bohemian massif in southern Germany. Rocks drilled are mainly paragneiss and metabasites (amphibolites, metagabro) (Pribnow and Winter, 1997). Measured data show lithology related variations in heat production.

\section{Fractal analysis}

A time/space series is said to follow fractal behavior, if its power spectrum, and variogram shows power law (scaling) characteristic with a non-zero scaling exponent (Srivastava and Sen, 2009, 2010; Dimri, 2000, 2005). Fractal behavior of various physical properties like density, susceptibility, reflectivity, electrical resistivity has been established by many authors (Maus and Dimri 1994, 1995, 1996; Leonardi and Kuempel, 1998, 1999; Vedanti and Dimri, 2003 etc.) by analyzing the spectral content of the data. The most common method to understand the fractal behavior is to analyze the Fourier amplitude spectrum of the data. We know that for random distributions the power spectrum is flat, but if power spectrum varies as a function of frequency, it is known as scaling or fractal distribution. The scaling spectra $S(f)$ is defined as

$S(f) \propto f^{\beta}$

where $f$ is the frequency and $\beta$ is the scaling exponent. The value of scaling exponent determines the persistence in the data. While dealing with space series, variation of power spectrum versus wave-number is studied. Wave number is defined as the reciprocal of the spatial interval of the data points. If the data points are not at regular spatial interval, then they are interpolated at regular spatial sample interval for estimation of the power spectrum. Since most of the geophysical data sets are space series, wave number term is widely used in place of frequency while calculating power spectrum of the data. Scaling exponent can be obtained by fitting a straight line to log-log plot of Fourier amplitude

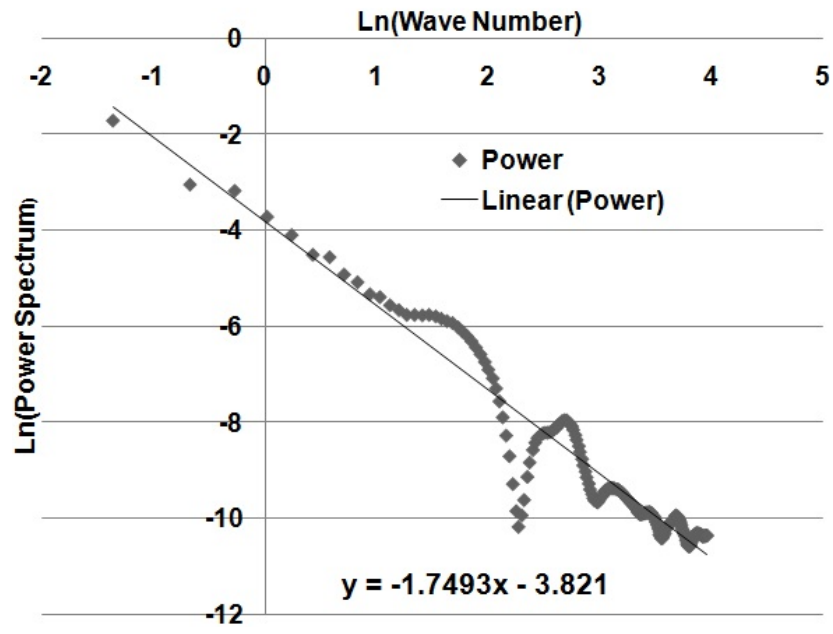

Fig. 1. Log-log plot of power spectrum of heat production data vs. wave number for the Dharwar craton of south Indian shield. Suitable linear equation was fit to the data to obtain the scaling exponent which is 1.7 , indicating fractal behavior in the data set. Linear fit indicates strong correlation between the adjacent points and substantiate power law regime in the data.

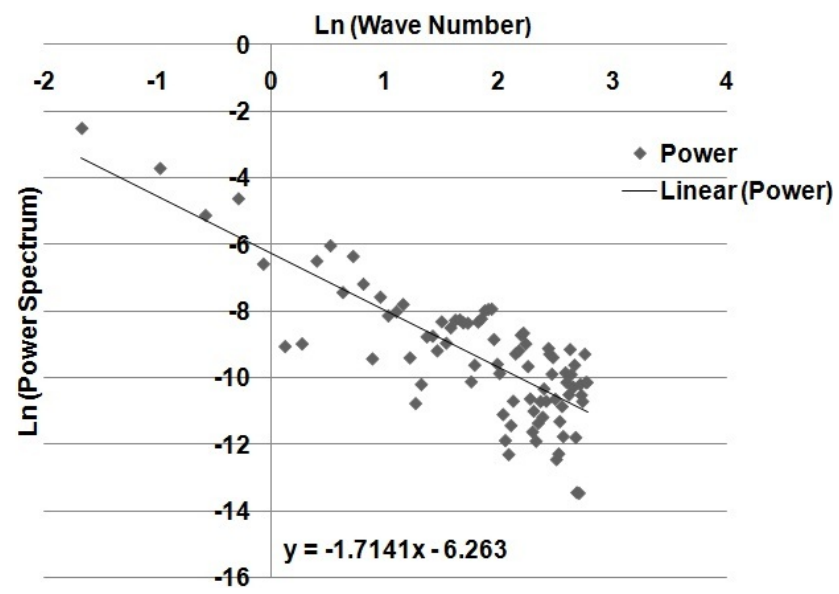

Fig. 2. Log-log plot of power spectrum of heat production data vs. wave number for the Northeastern Baltic shield. Suitable linear equation was fit to the data to obtain the scaling exponent which comes to 1.7 indicating fractal behavior in the data set. Variance in the data is also seen as revealed by scattered data points.

spectrum with wave number. The slope of the linear fit gives the value of scaling exponent. If the value of scaling exponent is less than 0.5 the data is non-fractal in nature.

The present analysis of the heat production data as shown in Table 1, together with that from the KTB borehole, shows that the heat generation follows the fractal behavior unlike the commonly assumed exponential variation. 


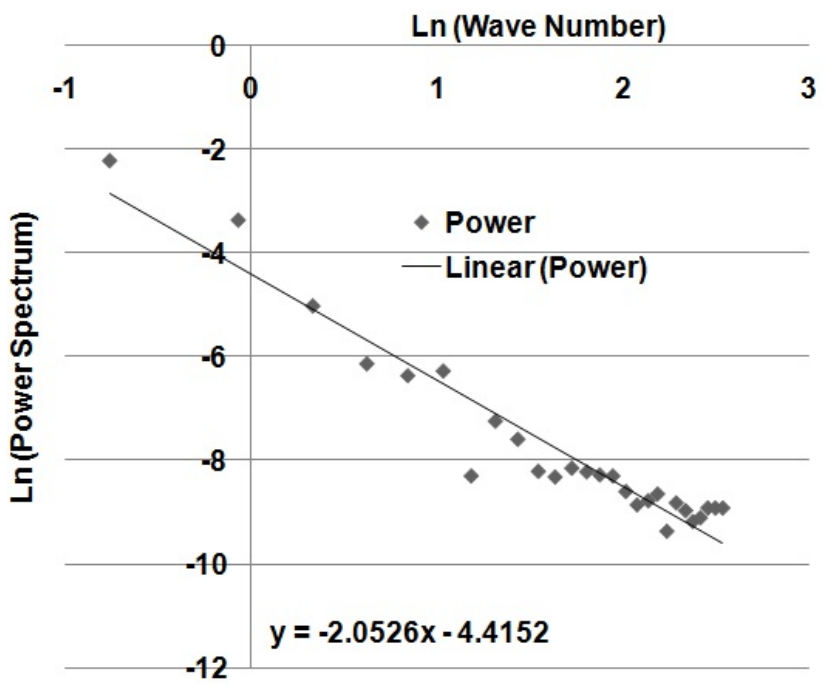

Fig. 3. Log-log plot of power spectrum of heat production data vs. wave number for the Vredefort granitic basement (Kaapvaal craton), South Africa. Best linear fit gives scaling exponent of 2.0, which conforms to fractal behavior in the data set. Strong correlation can be seen among data points.

Table 2. Scaling exponents of the analyzed vertical heat production profiles.

\begin{tabular}{ll}
\hline Area & $\begin{array}{l}\text { Scaling } \\
\text { Exponent }\end{array}$ \\
\hline Dharwar craton (Southern India) & 1.7 \\
Northeastern Baltic shield (Kola, Russia) & 1.7 \\
Kaapvaal craton (South Africa) & 2.05 \\
Hidaka metamorphic belt (Hokkaido, Japan) & 1.9 \\
Nissho pluton, Hidaka terrain (Hokkaido, Japan) & 1.6 \\
KTB (Germany) & 0.9 \\
\hline
\end{tabular}

\section{Results}

Power spectrum, experimental semi-variogram and rescaled range $(\mathrm{R} / \mathrm{S})$ analysis of the data have been carried out to detect the inherent power law behavior if any in the above mentioned crustal heat production data. All these methods indicate power law behavior in heat production data. Therefore, a detailed spectral analysis was carried out to give a possible power law model for the respective areas.

Figure 1 shows scaling exponent as obtained using spectral analysis of heat production data over the Dharwar craton (Southern India) to be approximately 1.7. Strong correlation can be seen between the adjacent data points from the linear fit. Similarly, Fig. 2 shows scaling exponent for the Northeastern Baltic shield, which is approximately 1.7. In this figure, the nature of scattered data points indicate variance in the data set. Figure 3 reveals scaling exponent of 2.0

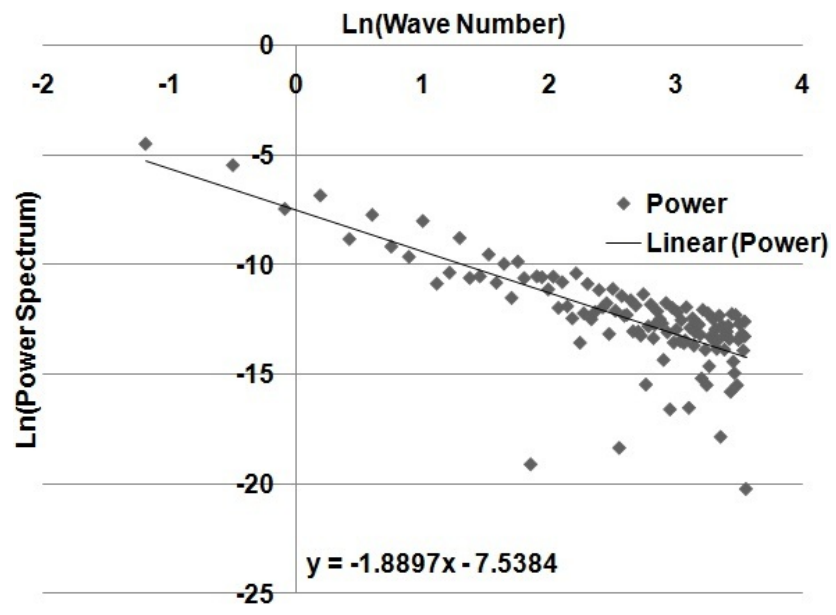

Fig. 4. Log-log plot of power spectrum of heat production data vs. wave number for the Hidaka metamorphic belt (Hokkaido, Japan). Best linear fit gives scaling exponent of 1.9 indicating presence of fractal behavior in the data set. Nature of linear fit indicates strong correlation between the adjacent points and substantiate power law regime in the data.

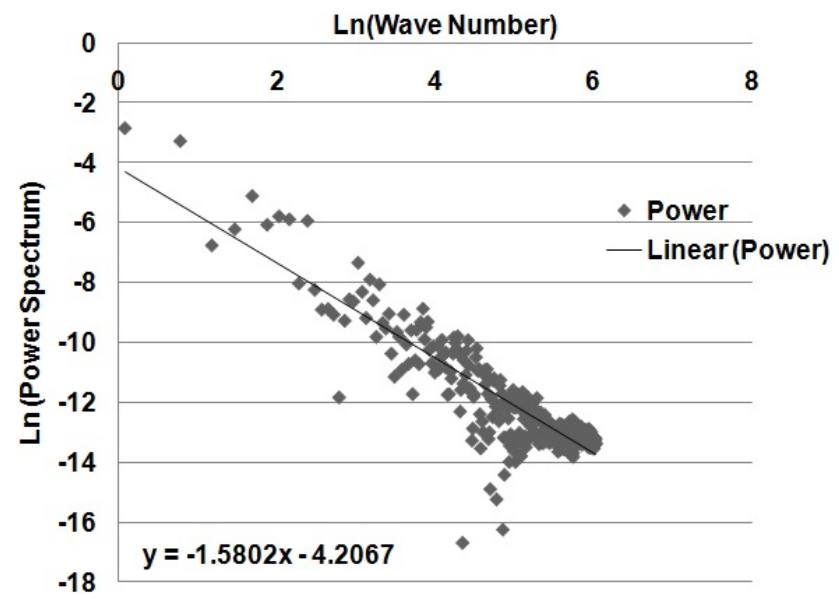

Fig. 5. Log-log plot of power spectrum of heat production data vs wave number for the Nissho pluton, Hidaka terrain (Hokkaido, Japan). Best linear fit gives scaling exponent of 1.6, indicating fractal behavior in the data set. This figure also shows a good correlation between adjacent data points.

for the Kaapvaal craton (South Africa). A very good linear fit has been obtained in this case indicating fractal behavior in the data set. Further, a strong linear correlation between the data points has been obtained for Hidaka metamorphic belt (Hokkaido, Japan). In this case, linear fit gives scaling exponent of 1.9 (Fig. 4). Similarly in case of Nissho pluton of Hidaka terrain (Hokkaido, Japan), scaling exponent is obtained as 1.6. In this case also,we get strong linear correlation between the data points (Fig. 5). However, a much lower value of scaling exponent $(0.9)$ has been obtained for 


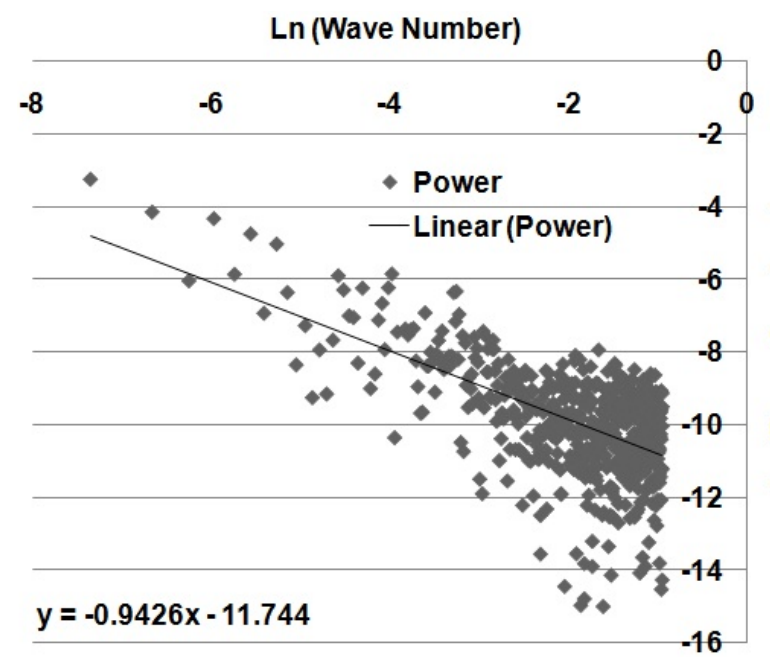

Fig. 6. Log-log plot of power spectrum of heat production data vs wave number for the KTB borehole (Germany). Computed linear fit gives a scaling exponent of 0.9 conforming to fractal behavior in the data set. Considerable scattering can be seen towards the lower wave number indicating high variability in the measured heat production. Value of scaling exponent, as obtained in this case, is much lower than that obtained for other cases.

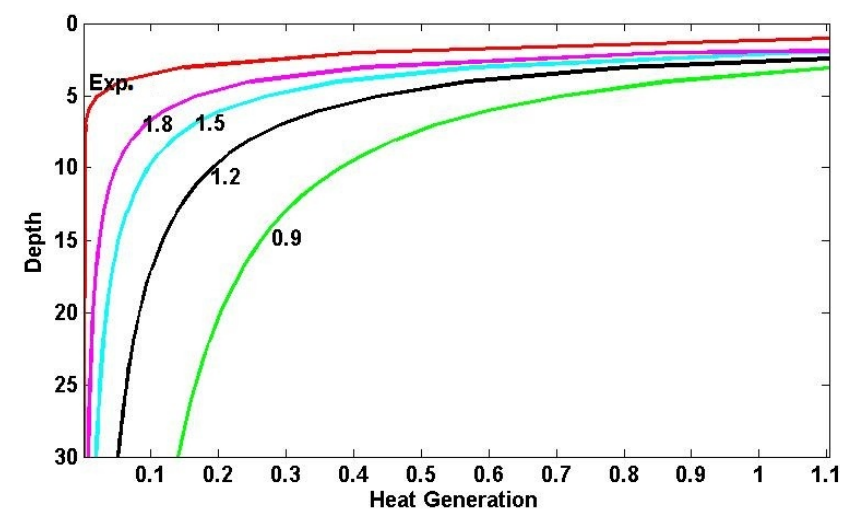

Fig. 7. Theoretical decay of exponential function (shown in red) and power law (for exponents 0.9,1.2,1.5 and 1.8 shown in green, black, cyan, and magenta respectively) with depth. Exponential function exhibits steeper decay than any power law exponent. This figure substantiates that the heat production decay follows power law as exponential decay is too steep to be real. This implies that less heat flow would be generated by radiogenic elements within the crust, if exponential model is assumed.

KTB borehole (Germany). Here, considerable scattering can be seen towards the lower wave numbers in the log-log plot of power spectrum vs. wave number, indicating high variability in the measured heat production. Scaling exponents, as obtained for different regions, are summarized in Table 2.
Table 3. Measured and computed heat production using exponential model (Eq. 1) with depth in Vredefort granitic basement, (Kaapvaal craton), South Africa.

\begin{tabular}{lcc}
\hline Depth $(\mathrm{km})$ & $\begin{array}{c}\text { Measured Heat Production A(z) } \\
\left(\mu \mathrm{W} \mathrm{m}^{-3}\right)\end{array}$ & $\begin{array}{c}\text { Computed Heat Production } \\
\text { (Exponential model Eq. 1) }\end{array}$ \\
\hline $6-7$ & 2.153 & 2.153 \\
$7-8$ & 2.374 & 1.95 \\
$8-9$ & 2.408 & 1.76 \\
$9-10$ & 2.123 & 1.59 \\
$10-11$ & 1.542 & 1.44 \\
$11-12$ & 1.488 & 1.31 \\
$12-13$ & 0.865 & 1.18 \\
$13-14$ & 0.869 & 1.07 \\
$14-15$ & 1.078 & 0.97 \\
$15-16$ & 1.095 & 0.88 \\
$16-17$ & 1.049 & 0.79 \\
$17-18$ & 0.945 & 0.72 \\
$18-19$ & 0.823 & 0.65 \\
$19-20$ & 0.97 & 0.59 \\
\hline
\end{tabular}

\section{Discussion}

It has been frequently assumed in the literature that the rate of heat production decreases exponentially throughout the crust. Such views were mainly based on the presumption that the earth's upper crust is made of radiogenically rich granitic-gneissic layer and radiogenically very poor lower crustal basaltic layer. However, this has not been the case. In many geological situations, it has been found that the measured heat production is considerably higher than normally assumed, at least till about mid-crustal level, for example, Vredefort granitic basement of Kaapvaal craton (Nicolaysen et al., 1981), central southern Alps region of the South Island, New Zealand (Pandey, 1981) and Archean Dharwar crust of India (Senthil Kumar and Reddy, 2004). Such midcrustal enrichment has been explained by lithology-related variations in heat producing elements.

For example, take the case of Vredefort region of South Africa. Here, the measured heat production in the crystalline basement (Tables 1,3 ) is considerably greater than the most published estimates of the heat production in the upper $20 \mathrm{~km}$ of the crust (Nicolaysan et al., 1981). Thus for this region, frequently assumed assumption that the heat production in the crust diminishes exponentially, does not hold good. Most likely, the middle crust of this region may contain high proportion of felsic rocks due to crustal differentiation, which results into the concentration of high heat producing elements in the upper and middle part of the crust.

In Table 3, we show the measured heat production in the crust along with the heat production values at similar depths, calculated using exponential decay model (Eq. 1) for Vredefort granitic basement (Kaapvaal craton) by taking initial value of heat production as $2.153 \mu \mathrm{W} \mathrm{m} \mathrm{m}^{-3}$, which is measured value at the surface of granitic basement. In such calculations " $D$ " which is the logarithmic decrement for an 
exponentially decreasing radioactive concentration, is conventionally taken as $10 \mathrm{~km}$. Significant discrepancy can be seen between the observed and calculated data sets (Table 3) indicating that exponential model does not fit to the observed data and provides much lower values at similar depths. Similar inferences can also be drawn, if we consider the heat production of $1.8,1.02$ and $0.18 \mu \mathrm{W} \mathrm{m}^{-3}$ for the upper, middle and lower continental crust, respectively as recommended by Rudnick and Fountain (1995), and deduce the comparative values using exponential model and taking the initial upper crustal heat production of $1.8 \mu \mathrm{W} \mathrm{m}{ }^{-3}$.

As explained earlier, while analyzing heat production vs. depth profiles for various continental regions, we found that heat production with depth follows the power law popularly known as fractal behavior. Scaling exponent estimated by the spectral analysis (Table 2) of the vertical heat production profiles, varied in the range of -0.9 to -2.0 . Minimum value of exponent has been found for KTB borehole, which is apparently related to higher heat production of gneisses. For other study areas, scaling exponent is found to be almost similar.

In Fig. 7 a comparative theoretical decay of heat production with depth for exponential as well as power law model for various scaling exponents is shown. From this figure, it can be seen that the lower scaling exponents are related to higher heat production, as is the case in KTB. This figure also reveals slower decay of heat production with depth in case of power law distribution compared to that of exponential decay. Thus, it would mean that more heat flow would be generated by radiogenic elements within the crust, if we assume power law model instead of exponential model. Consequently, in case of power law model, heat flow input from mantle would be lower compared to that of exponential model, which corroborates much better with the geologic observations and the rock types. Thus, fractal model appears to be more realistic in defining the decay of heat producing elements with depth. As mentioned earlier, in real geological situations, the crust is made up of four layers (granitic-gneissic, green schist, amphibolitic and granulitic facies) in which the metamorphic grade gradually increase. Corresponding lithologies thus gradationally range from felsic to intermediate to mafic in nature, till Moho depth is reached. Under such situation, crustal radioactivity is expected to decay slowly in conformity with fractal behavior. This inference will have significant impact in estimation of temperature-depth profiles in continental regions and also to how much heat from the underlying mantle is contributed to the crust. Thus, it will have serious relevance to rheological characters of the underlying crustal rocks.

Acknowledgements. We sincerely thank Non-Linear Geophysics group of AGU for inviting this manuscript. Assistance provided by Ms Uma Devi, NGRI is also acknowledged. We thank Director NGRI for his kind permission to publish this work.

Edited by: A. Surjalal Sharma

Reviewed by: two anonymous referees

\section{References}

Dimri, V. P.: Application of Fractals in Earth Sciences, edited by: Dimri, V. P., Oxford \& IBH Publishing Co. PVT LTD., New Delhi, 238 pp., 2000.

Dimri, V. P.: Fractal Behaviour of the Earth System, edited by: Dimri, V. P., Springer, New York, 207 pp., 2005.

Furukawa, Y. and Uyeda, S.: Thermal state under the Tohoko Arc with consideration of crustal heat generation, Tectonophysics, 164, 175-187, 1989.

Kremenetsky, A. A., Milanovsky, S. Y. U., and Ovchinnikov, L. N.: A heat generation model for continental crust based on deep drilling in the Baltic Shield, Tectonophysics, 159, 231-246, 1989.

Lachenbruch, A. H.: Preliminary geothermal model of the Sierra Nevada, J. Geophys. Res., 73, 6977-6989, 1968.

Lachenbruch, A. H.: Crustal temperature and heat production: Implications of the linear heat flow relation, J. Geophys. Res., 75, 3291-3300, 1970.

Leonardi, S. and Kuempel, H. J.: Variability of geophysical log data and the signature of crustal heterogeneities at the KTB, Geophys. J. Internat., 135, 964-974, 1998.

Leonardi, S. and Kuempel, H. J.: Fractal variability in KTB for crustal heterogeneities, Tectonophysics, 301, 173-181, 1999.

Maus, S. and Dimri, V. P.: Scaling properties of potential fields due to scaling sources, Geophys. Res. Lett., 21, 891-894, 1994.

Maus, S. and Dimri, V. P.: Potential field power spectrum inversion for scaling geology, J. Geophys. Res., 100, 12605-12616, 1995.

Maus, S. and Dimri, V. P.: Depth estimation from the scaling power spectrum of potential field, Geophys. J. Internat., 124, 113-120, 1996.

Nicolaysen, L. O., Hart, R. J., and Gale, N. H.: The Vredefort radioelement profile extended to supracrustal strata at Carleton Ville, with implications for continental heat flow, J. Geophys. Res., 86, 10653-10661, 1981.

Pandey, O. P.: Terrestrial heat flow in New Zealand, Ph.D. Thesis, Victoria University of Wellington, 194 pp., 1981.

Pribnow, D. F. C. and Winter, H. R.: Radiogenetic heat production in the upper third of continental crust from KTB, Geophys. Res. Lett., 24, 349-352, 1997.

Ray, L., Senthil Kumar, P., Reddy, G. K., Roy, S., Rao, G. V., Srinivasan, R., and Rao, R. U. M.: High mantle heat flow in a Precambrian granulite province: Evidence from southern India, J. Geophys. Res., 108, 2084, doi:10.1029/2001/JB000688, 2003.

Rudnick, R. L. and Fountain, D. M.: Nature and composition of the continental crust: a lower crustal perspective, Rev. Geophys., 33, 267-309, 1995.

Senthil Kumar, P. and Reddy, G. K.: Radioelements and heat production of an exposed Archean crustal cross-section, Dharwar craton, South India, Earth Planet. Sci. Lett., 224, 309-324, 2004.

Srivastava, R. P. and Sen, M. K.: Fractal based stochastic inversion of poststack seismic data using very fast simulated annealing, J. Geophys. Eng., 6, 412-425, 2009.

Srivastava, R. P. and Sen, M. K.: Stochastic inversion of prestack seismic data using fractal based prior, Geophysics, 75(3), R47R59, doi:10.1190/1.3379322, 2010.

Vedanti, N. and Dimri, V. P.: Fractal behavior of electrical properties in oceanic and continental crust, Indian J. Mar. Sci., 32(4), 273-278, 2003. 